\title{
Effect of epinephrine on the absorption of lidocaine following application to the oral mucosa in rats
}

\author{
Rui Sasaki and Katsuhisa Sunada*
}

\begin{abstract}
Background: We investigated the role of epinephrine in prolonging the localization of lidocaine on the oral mucosa and inhibiting its absorption in the blood of rats.

Methods: We used 7-8-week-old pathogen-free Wistar male rats $(n=128)$ for our study. We divided them into the control group administered with ${ }^{14} \mathrm{C}$-labeled lidocaine hydrochloride gel only and the study group administered with ${ }^{14} \mathrm{C}$-labeled lidocaine hydrochloride gel with epinephrine. The medications were administered in the palatal mucosa of the rats. The amount of mucosa, palatine bone, and serum lidocaine was measured by radioactivity using a liquid scintillation counter and was observed using autoradiograms.
\end{abstract}

Results: Initially, there was no significant difference in the lidocaine levels between the lidocaine and lidocaine with epinephrine groups in the palatal mucosa (751.9 $\pm 133.8 \mathrm{vs}$. $669.8 \pm 101.6 \mathrm{ng} / \mathrm{mg}[2 \mathrm{~min}])$. After $4 \mathrm{~min}$, the values were significantly lower in the lidocaine with epinephrine group (1040.0 $\pm 142.8 \mathrm{vs} .701 .2 \pm 109.0 \mathrm{ng} / \mathrm{mg}$ [20 min]). After $40 \mathrm{~min}$, the lidocaine level became significantly higher in the lidocaine with epinephrine group (586.8 $\pm 112.4 \mathrm{vs}$. $1131.3 \pm 155.2 \mathrm{ng} / \mathrm{mg}$ [40 min]). Similar results were observed in the palatine bone and serum.

Conclusion: Epinephrine prolonged the localization of lidocaine applied to the mucosa and inhibited its absorption into the bloodstream of rats. Clinical studies are required to evaluate the use of epinephrine-containing topical anesthetics on the oral mucosa.

Keywords: Epinephrine, Topical anesthesia, Lidocaine, Oral mucosa

\section{Background}

Dental topical anesthetics are not only used to numb the injection site but also for minor soft tissue surgeries $[1,2]$, extractions [3, 4], and suppression of the gag reflex [5]. Lidocaine is a widely used injectable local anesthetic that may also be used topically. However, the duration of lidocaine may be inadequate due to its short half-life. The oral soft tissues have a rich network of capillaries that causes rapid absorption of lidocaine after its

\footnotetext{
*Correspondence: katsu.sunada@nifty.com

Department of Dental Anesthesiology, School of Life Dentistry at Tokyo,

The Nippon Dental University, 1-9-20 Fujimi, Chiyoda-ku, Tokyo 102-8159, Japan
}

application. Using large doses of lidocaine may result in systemic toxicity. The application of large doses of benzocaine, which is also widely used as a dental topical anesthetic, to the oral mucosa causes methemoglobinemia [6]. These side effects can be prevented by inhibiting local anesthetic absorption, which can be achieved by inducing the contraction of local blood vessels. Epinephrine, which has a powerful vasoconstrictive effect, is added to dental lidocaine injections for this purpose. However, as the mucosal permeability of epinephrine is low [7], its addition to topical anesthetics neither extends the duration of anesthetic action nor prevents its rapid absorption from the mucosa [7-10]. Dental topical anesthetics 
containing epinephrine are not currently used. In the past, tetracaine and cocaine with added epinephrine were widely used as topical anesthetics for the skin $[11,12]$. A topical anesthetic containing lidocaine, tetracaine, and epinephrine was developed, and studies were conducted to determine its efficacy and safety $[13,14]$. The efficacy of other cutaneous topical anesthetics has also been studied $[15,16]$, and the addition of epinephrine has been regarded as an effective method of obtaining a sufficient anesthetic effect [17]. Hence, it is worth reinvestigating the effect of epinephrine with topical anesthetics on the oral mucosal surface since no specific study has yet fully explored this effect. Intra-oral injections would be more comfortable and safer if epinephrine could increase the topical anesthetic effect. Capillaries running immediately beneath the mucosa, which lacks a cornified epithelium, are believed to be more susceptible to the effect of epinephrine than those under the skin. We hypothesized that epinephrine prolongs the anesthetic effect of topical lidocaine on the oral mucosa. The primary outcome of this study was the amount of lidocaine in the oral mucosa and in the serum of rats when topical anesthetic was used with added epinephrine.

\section{Methods}

This study was approved by the Animal Experiment Committee of the Nippon Dental University School of Life Dentistry (approval No. 10-29) and was conducted in accordance with the guidelines laid down by ARRIVE (Animal Research: Reporting of in vivo Experiments).

\section{Animals}

One hundred and twenty-eight 7-8-week-old pathogenfree Wistar male rats (Tokyo Laboratory Animals Science Co., Ltd., Tokyo, Japan) were used for this study. We divided the rats into two groups: the control group administered with lidocaine only, and the treatment group administered with lidocaine with epinephrine. Each group included 64 animals. Two rats per cage were housed in the animal room of the University's isotope facility and were given unrestricted access to water and food.

\section{Formulation of test drugs}

\section{(a) Lidocaine}

We dissolved $3.5 \mathrm{~g}$ of carboxymethyl cellulose sodium salt $(\mathrm{CMC})$ in $100 \mathrm{~mL}$ of $2 \%$ lidocaine hydrochloride solution to formulate a $2 \%$ lidocaine hydrochloride gel.

Then, we added $25 \mu \mathrm{L}$ of ${ }^{14} \mathrm{C}$-labeled $2 \%$ lidocaine hydrochloride (American Radiolabeled Chemicals, Inc.,
St. Louis, MO, USA) and $5 \mu \mathrm{L}$ of $0.9 \%$ sodium chloride to $500 \mu \mathrm{L}$ of $2 \%$ lidocaine hydrochloride gel.

\section{(b)Lidocaine with epinephrine}

We added $5 \mu \mathrm{L}$ of $1 \mathrm{mg} / \mathrm{mL}$ epinephrine in place of $5 \mu \mathrm{L}$ of $0.9 \% \mathrm{NaCl}$ as used in (a).

Indigo carmine dye was added to both test drugs to aid visibility in order to excise the correct area of maxillary tissue.

\section{Lidocaine measurement}

Lidocaine was measured according to the method described by Akimoto et al. [18].

\section{(a) Sample collection}

Rats were administered pentobarbital $(50 \mathrm{mg} / \mathrm{kg})$ intraperitoneally for inducing sleep and were placed on their backs. A $5 \mu \mathrm{L}$ dose of both the test drugs was applied to the oral mucosae of the animals of corresponding test groups using an applicator tip with an internal diameter of $2 \mathrm{~mm}$ and a length of $4 \mathrm{~mm}$. This drug application was at the intersection of the midline of the palate and a line joining the centers of the bilateral second molars (Fig. 1). Samples of the maxilla and oral mucosa were collected from 100 rats, serum was collected from 24 rats, and autoradiographs were recorded for 4 rats.

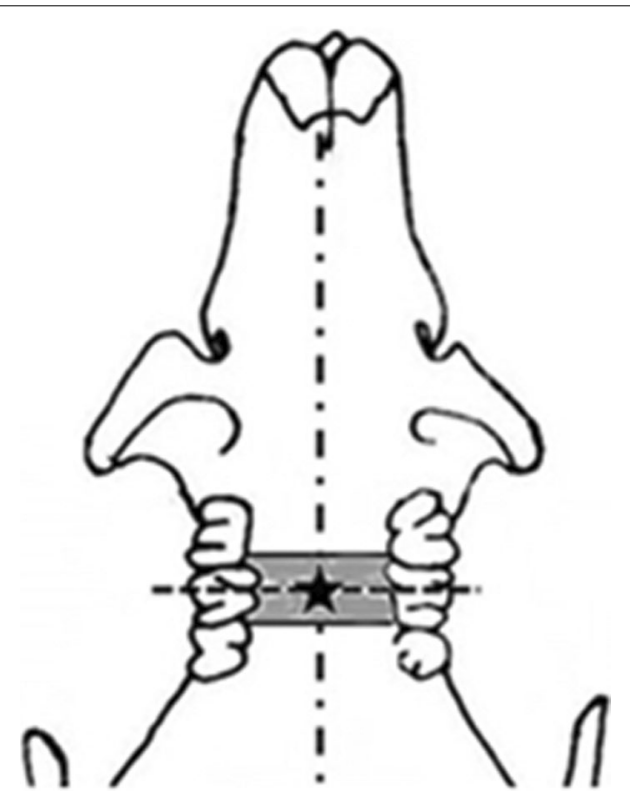

Fig. 1 Application area of test drugs. Asterisk: indicate of application area. This point was the intersection of the midline of the palate and a line joining the centers of the bilateral second molars 


\section{(i) Maxillary tissue}

One hundred rats (50 rats from each study group) were used for tissue measurement. A total of 10 time points were used in the study: $0.5,2,4,7,10,20,30$, 40,50 , and $60 \mathrm{~min}$ after application. Sleeping rats were decapitated with a guillotine and the gel remaining on the surface of the mucosa was removed with cotton swabs. Thus, there were 5 samples at each time point. The drug-applied region was excised from the upper jaw using bone scissors, and the mucosa was separated from the bone using bone forceps. These samples of the mucosa and bone were minced with the bone scissors for radioactivity measurement.

\section{(ii) Serum}

Another 24 rats (12 rats from each study group) were used for serum evaluation. At 0.5, 2, 5, 10, 20, 30, 40, 50 , and $60 \mathrm{~min}$ after application, $0.4 \mathrm{~mL}$ blood was collected from the left femoral artery and centrifuged at $4{ }^{\circ} \mathrm{C}$ and $15,000 \times g$ for $20 \mathrm{~min}$ to obtain the serum. Thus, 12 blood samples for each time point were collected from each rat of both groups. The study animals were euthanized by intraperitoneal administration of $150 \mathrm{mg} / \mathrm{kg}$ pentobarbital sodium after sample collection.

\section{(b) Radioactivity measurements}

The collected samples of the maxillary tissue $(10-50 \mathrm{mg})$ or serum $(50 \mu \mathrm{L})$ were placed in a liquid scintillation counter vial, and $0.5 \mathrm{~mL}$ of tissue solubilizer (Solvable ${ }^{\circledR}$; PerkinElmer, Waltham, MA, USA) was added. This mixture was warmed and agitated at $60{ }^{\circ} \mathrm{C}$ for $2 \mathrm{~h}$, and $25 \mu \mathrm{L}$ of acetic acid was added to neutralize it.

To this solution, a liquid scintillation cocktail (AQUASOL- ${ }^{\circledR}$; PerkinElmer, Waltham, MA, USA) was added, and the resulting solution was left in the dark for $24 \mathrm{~h}$. Thereafter, the radioactivity $(\mathrm{dpm})$ was measured using a liquid scintillation counter (LEC-6100; Aloka, Tokyo, Japan).

The amount of lidocaine in the mucosa or palatine bone was calculated per wet weight of tissue $(\mathrm{ng} / \mathrm{mg}$ wet weight) from the measured value and specific activity. The amount of lidocaine in the serum was indicated in terms of ${ }^{14} \mathrm{C}$-radioactivity $(\mathrm{dpm} / \mathrm{mL})$.

\section{Autoradiography observations}

Autoradiography was conducted according to the method described by Hashimoto et al. [19].

(a) Section preparation
The remaining 4 rats (2 rats from each study group of lidocaine and lidocaine with epinephrine) were used for autoradiography. The same method of lidocaine measurement was followed as in the previous section. The maxilla was removed 10 and $40 \mathrm{~min}$ after lidocaine or lidocaine with epinephrine application, embedded in $\mathrm{CMC}$, and placed on hexane dry ice to prepare frozen

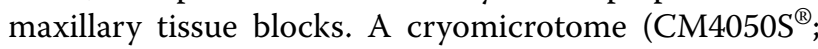
Leica Microsystems, Wetzlar, Germany) was then used to prepare coronal sections of $10 \mu \mathrm{m}$ thickness. These sections were placed on an adhesive sheet (Transfer Film ${ }^{\circledR}$; Leica Microsystems, Wetzlar, Germany) and dried.

\section{(b)Film observations}

The dried sections were pressed onto an $\mathrm{X}$-ray film (BioMax ${ }^{\circledR}$ XAR Film; Kodak, Rochester, NY, USA) and exposed to a temperature of $-80 \mathrm{C}$ for 40 days. The developed films were placed on sections stained with $0.25 \%$ eosin (Eosin ${ }^{\circledR}$; Nacalai Tesque Inc., Kyoto, Japan), and the radioactive isotope distribution was observed using a transmission scanner $\left(\right.$ GT $9500^{\circledR}$; EPSON, Nagano, Japan).

\section{Statistical analyses}

Measurements are indicated as means \pm standard deviations. Measurements at each time point were compared between the two groups using an unpaired t-test or Welch's t-test if unequal variance was observed, with $p<0.05$ regarded as significant. A software was used for statistical analyses (IBM SPSS ${ }^{\circledR}$ Statistics ver. 25; IBM Japan Ltd., Tokyo, Japan).

\section{Results \\ Lidocaine measurements}

\section{(a) Palatal mucosa}

There was no significant difference in the lidocaine levels in the first 2 min between the lidocaine group and the lidocaine with epinephrine groups. However, lidocaine values were significantly lower in the lidocaine with epinephrine group than in the other group at 4-20 min. After $30 \mathrm{~min}$, this significant difference was no longer evident. However, after $40 \mathrm{~min}$, the lidocaine level was significantly higher in the lidocaine with epinephrine group than in the other group (Table 1).

\section{(b) Palatine bone}

There was no significant difference in the lidocaine levels in the first 4 min between the two groups. However, 
Table 1 Amount of ${ }^{14} \mathrm{C}$-lidocaine in the palatal mucosa

\begin{tabular}{|c|c|c|c|}
\hline & $\begin{array}{l}\text { Lidocaine } \\
\text { Mean } \pm \text { SD }\end{array}$ & $\begin{array}{l}\text { Lidocaine with } \\
\text { epinephrine } \\
\text { Mean } \pm \text { SD }\end{array}$ & $p$ value \\
\hline Sample size & 5 & 5 & \\
\hline \multicolumn{4}{|l|}{ Time (min) } \\
\hline 0.5 & $371.5 \pm 48.4$ & $423.9 \pm 71.2$ & 0.210 \\
\hline 2 & $751.9 \pm 133.8$ & $669.8 \pm 101.6$ & 0.306 \\
\hline 4 & $813.5 \pm 41.2$ & $612.2 \pm 56.2$ & $<0.001$ \\
\hline 7 & $948.3 \pm 104.9$ & $583.7 \pm 47.5$ & $<0.001$ \\
\hline 10 & $1216.6 \pm 156.7$ & $658.5 \pm 92.0$ & $<0.001$ \\
\hline 20 & $1040.0 \pm 142.8$ & $701.2 \pm 109.0$ & 0.003 \\
\hline 30 & $940.1 \pm 144.2$ & $881.0 \pm 84.7$ & 0.452 \\
\hline 40 & $586.8 \pm 112.4$ & $1131.3 \pm 155.2$ & $<0.001$ \\
\hline 50 & $481.0 \pm 53.2$ & $995.2 \pm 156.4$ & $<0.001$ \\
\hline 60 & $306.6 \pm 109.0$ & $621.5 \pm 137.7$ & 0.004 \\
\hline
\end{tabular}

Data presented as the mean amount of lidocaine in $\mathrm{ng} / 1 \mathrm{mg}$ mucosa $p$ value compares lidocaine versus lidocaine with epinephrine Unpaired t-test was used to compare means $S D$ standard deviation

at 7-20 $\mathrm{min}$, the lidocaine values were significantly lower in the lidocaine with epinephrine group than in the other group. From 30 min onwards, the lidocaine levels were significantly higher in the lidocaine with epinephrine group than in the other group (Table 2).

(iii) Serum

Table 2 Amount of ${ }^{14} \mathrm{C}$-lidocaine in the palatal bone

\begin{tabular}{|c|c|c|c|}
\hline & $\begin{array}{l}\text { Lidocaine } \\
\text { Mean } \pm \text { SD }\end{array}$ & $\begin{array}{l}\text { Lidocaine with } \\
\text { epinephrine } \\
\text { Mean } \pm \text { SD }\end{array}$ & $p$ value \\
\hline Sample size & 5 & 5 & \\
\hline \multicolumn{4}{|l|}{ Time (min) } \\
\hline 0.5 & $1.8 \pm 0.4$ & $1.9 \pm 0.5$ & 0.738 \\
\hline 2 & $3.9 \pm 0.6$ & $4.3 \pm 0.6$ & 0.378 \\
\hline 4 & $3.1 \pm 0.9$ & $2.9 \pm 0.6$ & 0.769 \\
\hline 7 & $5.2 \pm 0.5$ & $3.6 \pm 0.9$ & 0.011 \\
\hline 10 & $10.3 \pm 2.2$ & $3.7 \pm 0.6$ & 0.002 \\
\hline 20 & $7.4 \pm 0.8$ & $4.4 \pm 0.6$ & $<0.001$ \\
\hline 30 & $4.3 \pm 0.8$ & $6.8 \pm 0.6$ & 0.001 \\
\hline 40 & $3.4 \pm 0.7$ & $9.9 \pm 1.2$ & $<0.001$ \\
\hline 50 & $2.6 \pm 0.6$ & $6.6 \pm 0.6$ & $<0.001$ \\
\hline 60 & $1.7 \pm 0.8$ & $3.5 \pm 0.8$ & 0.008 \\
\hline
\end{tabular}

Data presented as the mean amount of lidocaine in $\mathrm{ng} / 1 \mathrm{mg}$ bone $p$ value compares lidocaine versus lidocaine with epinephrine Unpaired t-test or Welch's test if unequal variance used to compare means $S D$ standard deviation
There was no significant difference in the lidocaine levels in the first $5 \mathrm{~min}$ between the lidocaine and lidocaine with epinephrine groups. However, after $5 \mathrm{~min}$, and up to and inclusive of $20 \mathrm{~min}$, the lidocaine levels were significantly lower in the lidocaine with epinephrine group than in the other group. After $30 \mathrm{~min}$, this difference was no longer significant, although after $40 \mathrm{~min}$, the lidocaine values were significantly higher in the lidocaine with epinephrine group (Table 3).

\section{Film observations}

When epinephrine was added, the amount of radioactivity was lower after $10 \mathrm{~min}$ and higher after $40 \mathrm{~min}$ compared with that of lidocaine alone (Fig. 2).

\section{Discussion}

The addition of epinephrine to lidocaine increased the time required for peak lidocaine concentration in the palatal mucosa and maxillary bone. The concentration of lidocaine in the mucosa peaked at around $10 \mathrm{~min}$ after application. When epinephrine was added, lidocaine concentration peaked at around $40 \mathrm{~min}$. If the lidocaine concentration in the mucosa is correlated with its topical anesthetic effect, then the addition of epinephrine extends the duration of this effect.

Conversely, the slower rate of increase in lidocaine concentration in the mucosa may delay the onset of its effect as a topical anesthetic. However, studies have found that an adequate anesthetic effect is achieved within 1-3 min of its application to the gingival mucosa $[20,21]$. In this study, the addition of epinephrine did not significantly affect lidocaine concentration up to $2 \mathrm{~min}$ after

Table 3 Radioactivity of ${ }^{14} \mathrm{C}$-lidocaine in the serum

\begin{tabular}{lllr}
\hline & $\begin{array}{l}\text { Lidocaine } \\
\text { Mean } \pm \text { SD }\end{array}$ & $\begin{array}{l}\text { Lidocaine with } \\
\text { epinephrine } \\
\text { Mean } \pm \text { SD }\end{array}$ & $p$ value \\
\hline Sample size & 12 & 12 & \\
Time (min) & $19.1 \pm 9.2$ & $15.6 \pm 6.7$ & 0.291 \\
0.5 & $21.8 \pm 10.4$ & $24.8 \pm 5.6$ & 0.383 \\
2 & $34.1 \pm 9.5$ & $30.7 \pm 6.6$ & 0.322 \\
5 & $55.9 \pm 4.3$ & $40.9 \pm 4.8$ & $<0.001$ \\
10 & $76.9 \pm 8.2$ & $48.4 \pm 8.6$ & $<0.001$ \\
20 & $63.4 \pm 7.8$ & $59.8 \pm 4.7$ & 0.189 \\
30 & $49.3 \pm 5.7$ & $70.2 \pm 4.4$ & $<0.001$ \\
40 & $34.8 \pm 7.3$ & $88.2 \pm 2.9$ & $<0.001$ \\
50 & $20.6 \pm 9.5$ & $81.0 \pm 4.8$ & $<0.001$ \\
\hline 60 & & & \\
\hline
\end{tabular}

Data presented as the mean of ${ }^{14} \mathrm{C}$ radioactivity in $\mathrm{dpm} / 1 \mathrm{~mL}$ serum $p$ value compares lidocaine versus lidocaine with epinephrine Unpaired t-test used to compare means $S D$ standard deviation 


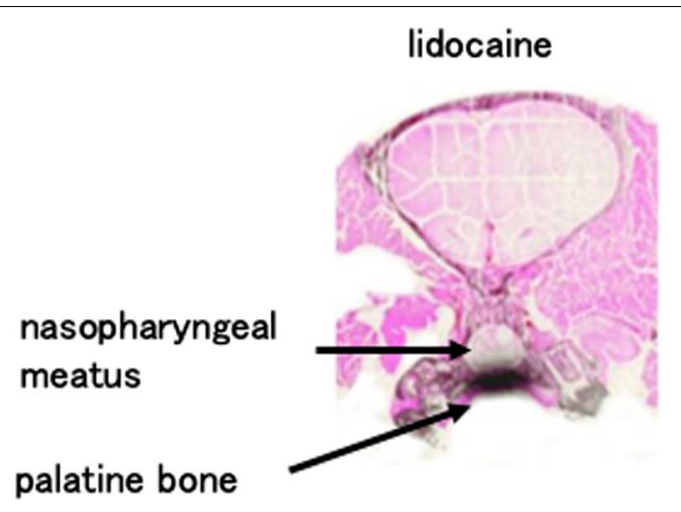

\section{lidocaine with epinephrine}
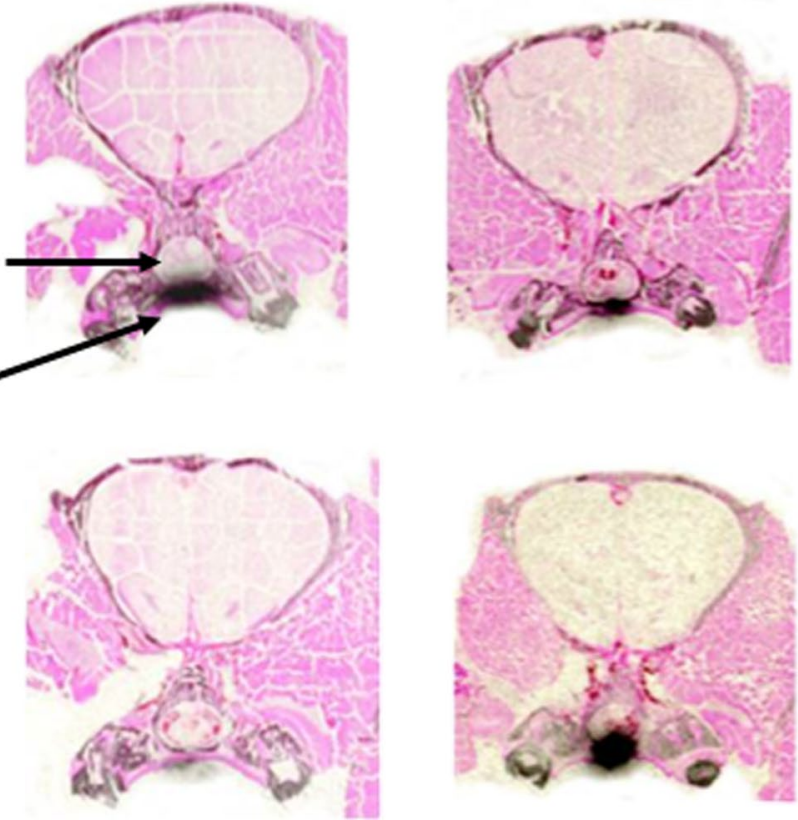

\section{0 minute}

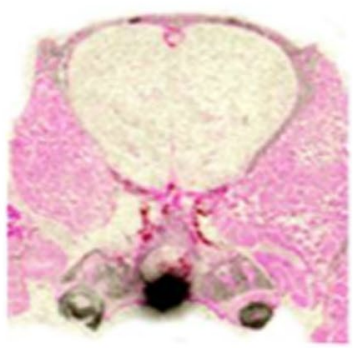

\section{0 minute}

Fig. 2 Autoradiograms of ${ }^{14} \mathrm{C}$-lidocaine in the coronary sections of maxilla. The maxilla removed at 10 and 40 min after the application of ${ }^{14} \mathrm{C}$-lidocaine (left) or ${ }^{14} \mathrm{C}$-lidocaine with epinephrine (left) was frozen, and a $10 \mu \mathrm{m}$ frontal section was sliced at the center of the site of drug application. The blackened area shows accumulation of ${ }^{14} \mathrm{C}$-lidocaine. After $40 \mathrm{~min}$, the blackened area increased in the maxillary section treated with lidocaine with epinephrine. In the maxillary section treated with lidocaine only, the blackened area almost disappeared

application. Therefore, we considered it unlikely that the addition of epinephrine delayed the onset of lidocaine's topical anesthetic effect.

With the addition of epinephrine, lidocaine still reached the maxillary bone after $40 \mathrm{~min}$ of application. The extended time for which lidocaine was localized in the mucosa may have increased the amount that penetrated the maxillary bone. This suggests that clinicians must wait sufficiently after application of epinephrinecontaining topical anesthetics before the initiation of invasive procedures, such as injection and deciduous tooth extraction.

As the oral mucosa is rich in capillaries, topical anesthetics are rapidly absorbed into the bloodstream. Although no studies have been performed on the human oral mucosa, when lidocaine is sprayed on the upper airway mucosa, the concentration in blood reportedly peaks after 5-30 $\mathrm{min}$ [22-25]. This rapid rise of lidocaine concentration in blood is more likely to cause toxicity [10, $26,27]$. In our study, the time required to reach the peak blood lidocaine concentration was increased from 20 to $50 \mathrm{~min}$ after application due to the addition of epinephrine. This indicated that epinephrine inhibits the absorption of lidocaine into the bloodstream, thus lowering the rate at which the blood concentration rises. However, the peak concentration in the blood was higher when epinephrine was added. These findings warrant further studies to investigate the effect of epinephrine on the risk of local anesthetic toxicity. It has also been reported that it may affect the synthesis of methemoglobin, which occurs as a result of the metabolism of local anesthetics [28].

Campbell et al. [10] and Adrian et al. [26] reported that the addition of epinephrine to the topical tetracaine applied to the mucosa of the pyriform fossa and trachea neither prolonged the duration of anesthesia nor inhibited their absorption. Several other studies have reported that the anesthetic action of lidocaine applied to the mucosal surface peaked after 2-5 min. Epinephrine had low tissue permeability, and its addition to topical anesthetics had no effect on its duration of action [7, 9, 26]. As epinephrine is strongly polarized in aqueous solution, it is unable to pass through the cell membrane [29]. Since the cell membrane is composed of a lipid bilayer, it is more easily penetrated by fat-soluble substances, and as epinephrine is a water-soluble hormone with a receptor on the cell membrane surface, it has low fat solubility. This is the reason for its low tissue permeability.

The reasons for the difference between these reports and our results are unknown. However, it is possible that epinephrine had no effect on the capillaries running 
through the deep mucosa when applied to the surface. It may have only constricted the vessels running immediately beneath the mucosa to prolong the localization of lidocaine. This suggests that it may not be necessary for epinephrine to permeate the deep mucosa to inhibit the absorption of topical anesthetics into the bloodstream. We also accurately measured the lidocaine concentration in tissues using radioisotopes, while all previous reports were clinical studies. It is possible that epinephrine's effect may not be sufficient to affect the clinical action of anesthetics. As the addition of epinephrine delayed the increase in lidocaine concentration in the mucosa from 4 min after application, the possibility that previous studies may have measured its effect before the complete manifestation of its anesthetic action cannot be excluded.

This study has some limitations. We did not directly measure the anesthetic effect of lidocaine with epinephrine. We also did not investigate the suppression of toxicity or methemoglobinemia. Further clinical research to evaluate the effects of local anesthesia with epinephrine and animal studies to determine the decreasing effect for systemic toxicity of anesthetics and blood concentration of methemoglobin are required.

The results of this study demonstrated that epinephrine prolonged the localization of lidocaine applied to the oral mucosa and inhibited its absorption into the bloodstream. Therefore, further studies are required to investigate the clinical application of epinephrine-containing topical anesthetics on the oral mucosa. Use of epinephrine-containing topical anesthetics could make oral injections less painful and safer during dental procedures.

\section{Acknowledgements}

We express our profound gratitude to Dr. Mikiko Yamashiro of the Department of Dental Anesthesiology for her advice and comments, and to Dr. Shuichi Hashimoto and all the staff of the Dental Research Institute Radio Isotope Center.

\section{Authors' contributions}

KS: Conceptualization, Formal analysis, Supervision, Validation, Review \& editing. RS: Data curation, Formal analysis, Investigation, Original draft writing. Both authors read and approved the final manuscript.

\section{Funding}

The authors have no sources of funding to declare for this manuscript.

\section{Availability of data and materials}

The datasets generated during the current study are available in the Mendeley repository, Sunada K., Sasaki R. (2021). Effect of Epinephrine on the Absorption of Lidocaine Following Application to the Oral Mucosa in Rats. https://doi.org/10. 17632/65pz7shjxy.1.

\section{Declarations}

\section{Ethics approval and consent to participate}

This study was approved by the Animal Experiment Committee of the Nippon Dental University School of Life Dentistry (approval No. 10-29). All methods were carried out in accordance with the guidelines laid down by the revised Animals (Scientific Procedures) Act 1986 in the UK, Directive 2010/63/EU in Europe and ARRIVE (Animal Research: Reporting of in vivo Experiments).
Consent for publication

Not applicable.

\section{Competing interests}

The authors declare that they have no competing interests.

Received: 20 January 2021 Accepted: 19 June 2021

Published online: 01 July 2021

\section{References}

1. Meechan JG. The use of EMLA for an intra-oral biopsy in a needle phobic: a case report. Anesth Prog. 2001;48:32-4.

2. Roller NW, Ship II. Lidocaine topical film strip for oral mucosal biopsies. J Oral Med. 1975;30:55-8.

3. Gangarosa LP. Iontophoresis for surface local anaesthesia. J Am Dent Assoc. 1974;88:125-8. https://doi.org/10.14219/jada.archive.1974.0038.

4. Taware CP, Mazumdar S, Pendharkar M, MPharm, Adani MH, Devarajan PV. A bioadhesive delivery system as an alternative to infiltration anaesthesia. Oral Surg Oral Med Oral Path. 1997;84:609-15. https://doi.org/10.1016/ S1079-2104(97)90360-7.

5. Lee HS. Recent advances in topical anesthesia. J Dent Anesth Pain Med. 2016:16:237-44. https://doi.org/10.17245/jdapm.2016.16.4.237.

6. Warren OU, Blackwood B. Acquired methemoglobinemia. N Engl J Med. 2019;381:1158. https://doi.org/10.1056/nejmicm1816026.

7. Catterall W, Mackie K. Local anesthetics. In: Hardman JG, Limbird LE, editors. Goodman \& Gilman's the pharmacological basis of therapeutics. 9th ed. New York: McGraw-Hill Professional; 1996. p. 341.

8. Adriani J, Zepernick R. Some recent studies on the clinical pharmacology of local anesthetics of practical significance. Ann Surg. 1963;158:666-71. https://doi.org/10.1097/00000658-196310000-00013.

9. Löfström B. Aspects of the pharmacology of local anesthetic agents. Br J Anaesth. 1970;42:194-206. https://doi.org/10.1093/bja/42.3.194.

10. Campbell D, Adriani J. Absorption of local anesthetics. JAMA. 1958;168:873-7.

11. Pryor GJ, Kilpatrick WR, Opp DR. Local anesthesia in minor lacerations: topical TAC vs lidocaine infiltration. Ann Emerg Med. 1980;9:568-71. https://doi.org/10.1016/S0196-0644(80)80227-7.

12. Smith SM, Barry RC. A comparison of three formulations of TAC (tetracaine, adrenaline, cocaine) for anesthesia of minor lacerations in children. Pediatr Emerg Care. 1990;6:266-70. https://doi.org/10.1097/ 00006565-199012000-00004.

13. Ernst AA, Marvez-Valls E, Nick TG, Chin E, Wood E, Gonzaba WT. Lidocaine, adrenaline, tetracaine gel versus tetracaine, adrenaline, cocaine gel for topical anesthesia in linear scalp and facial lacerations in children aged 5-17 years. Pediatrics. 1995;95:255-8.

14. Ernst AA, Marvez-Valls E, Nick TG, Mills T, MinVielle L, Houry D. Topical lidocaine adrenaline tetracaine (LAT Gel) versus injectable buffered lidocaine for local anesthesia in laceration repair. WJM. 1997;167:79-81.

15. Bush S. Is cocaine needed in topical anaesthesia? Ann Emerg Med. 2002;19:418-22. https://doi.org/10.1136/emj.19.5.418.

16. Kravitz ND. The use of compound topical anesthetics: a review. J Am Dent Assoc. 2007;138:1333-9. https://doi.org/10.14219/jada.archive.2007.0048.

17. Vinci RJ, Fish SS. Efficacy of topical anesthesia in children. Arch Pediatr Adolesc Med. 1996;150:466-9. https://doi.org/10.1001/archpedi.1996. 02170300020005

18. Akimoto T, Hashimoto S, Sunada K. Dexmedetomidine ( $12.5 \mathrm{lg} / \mathrm{mL})$ improves tissue distribution, anesthetic action, and hemodynamic effects of lidocaine after palatal infiltration in rats. Odontology. 2016;104:390-6. https://doi.org/10.1007/s10266-015-0221-6.

19. Hashimoto S, Yamashiro M, Fujita K, Yasuda A, Sunada K. Effects of epinephrine on lidocaine pharmacokinetics and blood volume in the dental pulp. J Endod. 2014;40:1370-4. https://doi.org/10.1016/j.joen.2014.02. 029.

20. Stern I, Giddon DB. Topical anesthesia for periodontal procedures. Anesth Prog. 1975;22:105-8.

21. Gill CJ, Orr DL II. A double blind crossover comparison of topical anesthetics. J Am Dent Assoc. 1979;98:213-4. https://doi.org/10.14219/jada. archive.1979.0476. 
22. Curran J, Hamilton C, Taylor T. Topical analgesia before tracheal intubation. Anaesthesia. 1975;30:765-8. https://doi.org/10.1111/j.1365-2044 1975.tb00952.x.

23. Bromage PR. Concentrations of lignocaine in the blood after intravenous, intramuscular epidural and endotracheal administration. Anaesthesia. 1961;16:461-78. https://doi.org/10.1111/j.1365-2044.1961.tb13426.x.

24. Scott DB, Littlewood DG, Covino BG, Drummond GB. Plasma lignocaine concentrations following endotracheal spraying with an aerosol. $\mathrm{Br} J$ Anaesth. 1976:48:899-902. https://doi.org/10.1093/bja/48.9.899.

25. Viegas O, Stoelting RK. Lidocaine in arterial blood after laryngotracheal administration. Anesthesiology. 1975;43:491-3. https://doi.org/10.1097/ 00000542-197510000-00019.

26. Adriani J, Campbell D. Fatalities following topical application of local anesthetics to mucous membranes. JAMA. 1956;162:1527-30. https://doi. org/10.1001/jama.1956.02970340017006.
27. Scott DB. Evaluation of clinical tolerance of local anaesthetic agents. Br J Anaesth. 1975:47(suppl):328-33.

28. Trapp L, Will J. Acquired Methemoglobinemia Revisited. Dent Clin N Am. 2010;54:665-75. https://doi.org/10.1016/j.cden.2010.06.007.

29. Nakamura S, Matsuura N, Ichinohe T. A new method of topical anesthesia by using anesthetic solution in a patch. J Endod. 2013;39:1369-73. https://doi.org/10.1016/j.joen.2013.07.019.

\section{Publisher's Note}

Springer Nature remains neutral with regard to jurisdictional claims in published maps and institutional affiliations.
Ready to submit your research? Choose BMC and benefit from:

- fast, convenient online submission

- thorough peer review by experienced researchers in your field

- rapid publication on acceptance

- support for research data, including large and complex data types

- gold Open Access which fosters wider collaboration and increased citations

- maximum visibility for your research: over $100 \mathrm{M}$ website views per year

At BMC, research is always in progress.

Learn more biomedcentral.com/submissions 